\title{
Ozone therapy in ethidium bromide-induced demyelination in rats: possible protective effect [abstract]
}

\author{
Mohga Samy
}

Egypt

ABSTRACT

\section{OPEN ACCESS}

\section{Citation}

Samy M. Ozone therapy in ethidium bromide-induced demyelination in rats: possible protective effect [abstract]. Proceedings of The World Conference on Ozone Therapy in Medicine, Dentistry and Veterinary. Ancona (Italy). September 22nd - 23rd - 24th , 2017. J Ozone Ther. 2019;3(4):34. doi: 10.7203/jo3t.3.4.2019.15518

Academic Editor

Jose Baeza-Noci,

School of Medicine, Valencia

University, SPAIN

\section{Editor}

World Federation of Ozone Therapy, Bolgna, ITALY

\section{Received}

June 17, 2019

\section{Accepted}

December 08, 2019

Published

December 30, 2019

\section{Intellectual Property}

Mohga Samy.

This is an open access article distributed under the terms of the Creative Commons Attribution License (CC BY 4.0), which permits unrestricted use, distribution, and reproduction in any medium, provided the original author and source are credited.

\section{Author Information}

mohga_sam@hotmail.com
Background. Multiple sclerosis is an autoimmune inflammatory disease of the central nervous system and it is characterized by excessive demyelination

Purpose. The study aim to investigate the possible protective effect of ozone (O3) in ethidium bromide (EB) induced demyelination in rats either alone or in combination with corticosteroid in order to decreases the dose of steroid therapy.

Material and Methods. Rats were divided into 7 groups:

- Group (1) normal control rats received saline.

- Group (2) sham-operated rats received saline.

- Group (3) sham operated rats received oxygen.

- Group (4) EB-treated rats received EB.

- Group (5) EB treated rats received oxygen.

- Group (6) EB treated rats received methyl prednisolone (MP)

- Group (7) EB treated rats received half the dose of MP concomitant with ozone.

Results. Significant improvement in the brain serotonin, dopamine, noradrenalin. A reduction of MDA,TNF-COX2 immune-reactivity was noticed in MP and oxygen groups .

Furthermore, best amelioration was achieved by combining half the dose of methyl-prednisolone with ozone..

Conclusion. We concluded that ozone has a protective effect on demyelination and can be used due to its protective effect in demyelinating diseases such as multiple sclerosis. 